Original

Article

\title{
The effect of bilateral uterine artery ligation versus intermittent clamping of uterine and ovarian artery on blood loss during abdominal myomectomy : A randomized controlled trial
}

\author{
Hesham M. Fathy*, Haitham El Sabae, Ahmed M. EL-Kotb, Yasmine H. Mohamed \\ Department of Obstetrics and Gynecology, Faculty of Medicine, Ain-Shams University, Cairo, \\ Egypt
}

\begin{abstract}
Background: Myomectomies are more commonly performed than hysterectomies, mainly due to the fact that patients desire to retain their uterus for psychological, reproductive and cultural reasons even after completing their families. The average volume of blood loss during abdominal myomectomy is 200 to $800 \mathrm{~mL}$. Surgical hemorrhage may result in anemia, hypovolemia, and coagulation abnormalities.

Aim: To compare between bilateral uterine artery ligation and intermittent clamping of uterine and ovarian artery on amount of blood loss during abdominal myomectomy.

Patients and Methods: This study was conducted at Ain-Shams University Maternity Hospital on 90 women with symptomatic myomas in the postmenstrual period presented by abnormal uterine bleeding, dull aching lower abdominal pain, dyspareunia, pressure symptoms, progressive abdominal enlargement or pelvic heaviness, diagnosed based on clinical examination and ultrasound scan with pre-operative hemoglobin level above $10 \mathrm{gm} / \mathrm{dl}$.

Results: The preoperative $\mathrm{Hb}$ was $11.6 \mathrm{gm} \%$ and $11.8 \mathrm{gm} \%$ for both clamping and ligation one respectively, and postoperative $\mathrm{Hb}$ for the groups was $9.4 \mathrm{gm} \%$ and $9.2 \mathrm{gm} \%$ for the 2 groups respectively. There was no significant difference between both groups regarding postoperative drop of hemoglobin which was $0.8 \mathrm{gm} \%$ in the clamping group and 1.1 $\mathrm{gm} \%$ in the ligation group. Estimated inraoperative blood loss start was significantly fewer among clamping group than among ligation group. Hemoglobin reduction was significantly fewer among clamping group than among ligation group. Conclusion: Based on the results obtained by this study, intermittent clamping of uterine and ovarian artery is a preferred approach than bilateral uterine artery ligation on blood loss during abdominal myomectomy.
\end{abstract}

Key Words: Abdominal myomectomy, bilateral uterine artery ligation, blood loss, hemorrhage, intermittent clamping, uterine, ovarian artery

Received: 1 October 2019, Accepted: 2 October 2019

Corresponding Author: Hesham M. Fathy, Department of Obstetrics and Gynecology, Faculty of Medicine, Ain-Shams University, Cairo, Egypt, Tel.: 01069491030, E-mail: fathihesham351@gmail.com

ISSN: 2090-7625, February 2020, Vol.10, No. 1

\section{INTRODUCTION}

Leiomyomata uteri (fibroids) are tumours of the smooth muscle and the connective tissue of the uterus ${ }^{[1]}$ with more than $50 \%$ of women older than 30 years having this benign tumour ${ }^{[2]}$.

The diverse symptomatology of fibroids can be attributed to size, number and location of the tumours. The common symptoms include the presence of an abdominal mass, menorrhagia and pressure effects ${ }^{[3]}$.

The standard treatment of symptomatic leiomyomas (myomas or fibroids) is hysterectomy for women who have completed childbearing and myomectomy for women who wish to preserve fertility. Myomectomy can be accomplished by laparotomy, laparoscopy, or hysteroscopy. Blood loss associated with the dissection of huge fibroids renders myomectomy a more technically challenging procedure than hysterectomy. A requirement for transfusion in up to $20 \%$ of cases following abdominal myomectomy has been reported in the literature, and in $2 \%$ of cases there is need for conversion of myomectomy to hysterectomy ${ }^{[4]}$.

Myomectomies are more commonly performed than hysterectomies, mainly due to the fact that patients desire to retain their uterus for psychological, reproductive and cultural reasons even after completing their families ${ }^{[5]}$.

In a study conducted in KSA comparing abdominal myomectomy versus abdominal hysterectomy for symptomatic and big uterine fibroid including 111 patients with symptomatic large fibroids 73 patients $(68,5 \%)$ 
underwent myomectomy compared to 38 patients $(34,2 \%)$ who underwent abdominal myomectomy . hysterectomy, internal iliac a ligation or other procedures were not necessary to control bleeding in patients who underwent myomectomy ${ }^{[6]}$.

Blood loss during myomectomy can be intraoperative or postoperative and with hematoma formation ${ }^{[7]}$.

Haemorrhage is still a great concern during myomectomy and expectedly, many methods have been reported for reducing such blood loss. The use of Bonney's clamp, intrauterine injection of Vasopressin, preoperative administration of drugs like GnRH, tranexamic acid and misoprostol and the use of a tourniquet have all been reported ${ }^{[8]}$.

As most of the blood enters the uterus through the uterine arteries, it was postulated that after occluding the arteries transient uterine ischemia occurs. The hypothesis proposes that soon after occlusion, the blood within the myometrium clots, the myometrium becomes hypoxic, and the metabolism shifts from oxidative pathways to anaerobic glycolysis. The hypothesis further postulates that hours later the clot within the myometrium lyses and the uterus is reperfused through the collateral arteries ${ }^{[9]}$.

As regarding uterine artery ligation in cases of abdominal myomectomy, ligation of the uterine vessels was done before myomectomy in all large myomas. Laparoscopic ligation of uterine arteries has been combined with myomectomy, with successful reduction in blood loss ${ }^{[10]}$. Most cases of large myomas can be devascularized before myomectomy by laparoscopic intracorporeal suturing of the uterine arteries. The uterine arteries can be ligated by an anterior approach or posterior approach depending on the location of the myoma. In case of lower segment myomas or cervical myomas, the uterine artery can be ligated at its origin from the anterior division of the internal iliac.

Ligation of the ascending branch of the uterine artery anteriorly is preferred during most laparoscopic myomectomies. The uterovesical fold of the peritoneum is opened and the bladder is pushed down. This moves the ureters laterally and prevents them being included in the suture. The uterine vessels are identified on either side and ligated. No. 1 delayed absorbable sutures are used for ligating the uterine vessels. There can be technical difficulties in approaching the uterine vessels in the case of large myomas. There can be some venous bleeding if the uterine vein is accidentally punctured. In such cases the suturing is completed and the venous bleed stops by itself. Once the uterines are occluded bilaterally, the myoma turns pale. This devascularized the myoma and decreases the blood loss during the procedure ${ }^{[11]}$
As regarding intermittent uterine artery clamping to reduce blood loss, the retroperitoneum is opened through adnexal triangle. After open the para-rectal space, the ureter was dissected carefully using a blunt dissector, bilateral uterine arteries were then identified and clamped by the bulldog clamp temporarily until the uterine incision had been sutured. After reducing the blood flow, the capsule of the myoma was incised and dissected using dissectors and scissors. The bleeding area of the myoma surface was coagulated using bipolar forceps. A screw was inserted into the myoma, and it was removed completely step by step. Finally, the edge of the uterine defect was sutured using V-locks. There was minimal blood loss $(<50 \mathrm{ml})$ during the operation ${ }^{[10]}$.

A previous study ${ }^{[1]}$ found that temporary clipping of the uterine arteries prior to laparoscopic myomectomy is a safe procedure for controlling bleeding without affecting the uterine blood supply nor the ovarian function.

Y. Lee et al., found that temporary clipping of both uterine arteries was safe and feasible, he performed single port access laparoscopic myomectomy with temporary clipping of both uterine arteries in 7 patients. His result showed that median value of $\mathrm{Hb}$ drop after surgery on day 1 and hospital stay were $2.3 \mathrm{~g} / \mathrm{dl}(0.3-3.8)$ and 3 days $(2-5)^{[12]}$.

Many previous studies have discussed the usage of intermittent clamping of uterine arteries and bilateral uterine arteries ligation in cases of laparoscopic myomectomy which has shown promising results. Although there is gap of knowledge in the literature regarding the usage of the above mentioned techniques in cases of abdominal myomectomy. Our study will focus on the comparison between bilateral uterine artery ligation and intermittent clamping of uterine arteries and utero-ovarian anastomosis on blood loss during abdominal myomectomy.

\section{AIM OF THE WORK}

The aim of the current study is to compare between bilateral uterine artery ligation and intermittent clamping of uterine and ovarian artery on amount of blood loss during abdominal myomectomy.

\section{PATIENTS AND METHODS}

This randomized controlled study was conducted at Ain-Shams University Maternity Hospital. The study was conducted on 90 women with symptomatic myomas in the postmenstrual period presented by abnormal uterine bleeding, dull aching lower abdominal pain, dyspareunia, pressure symptoms, progressive abdominal enlargement or pelvic heaviness, diagnosed based on clinical examination and ultrasound scan with pre-operative hemoglobin level above $10 \mathrm{gm} / \mathrm{dl}$ 
The study included women with ages (20-40 years), with symptomatic myomas in the postmenstrual period presented by ; abnormal vaginal bleeding, dull aching lower abdominal pain, dyspareunia, pressure symptoms and progressive abdominal enlargement or pelvic heaviness. Diagnosis of uterine fibroids was based on clinical examination and ultrasound scan. Patients with pre-operative hemoglobin level above $10 \mathrm{gm} / \mathrm{dl}$. Criteria of uterine myoma: Five or less symptomatic uterine myomas. Maximum diameter of the largest myoma is $6 \mathrm{~cm}$. Myomas may be subserous or intramural and uterine size less than 24 weeks pregnancy. Endometrial sampling was done to exclude any endometrial malignancy.

We excluded obese patients (body mass index $>30 \mathrm{~kg} / \mathrm{m} 2$ ), those with any medical comorbidities, those who received pre-operative hormonal therapy (such as a $\mathrm{GnRH}$ analogue) or anti-coagulation therapy.

\section{Ethical considerations:}

The study was approved from the ethics committee of the Department of Obstetrics and Gynecology, Faculty of Medicine, Ain-Shams University.

Informed written consent was taken from all participants before recruitment in the study, and after explaining the purpose, possible risks and complications (including possibility of blood transfusion and the possible need for hysterectomy) of different procedures carried out in the study.

All included women were subjected to the following; history taking with particular emphasis on past medical and menstrual history, general, abdominal and local examination. Ultrasonography was carried out to confirm the exact site, size and number of uterine myomas and to exclude any associated pelvic pathology. Venous blood sample for the assessment of Hemoglobin $(\mathrm{Hb})$ and hematocrit level was withdrawn before the operation for each case.

The study population was divided into 2 groups: Group A: Bilateral ascending uterine artery was ligated at internal os level by elevating the peritoneum and a small incision was done to isolate the uterine artery. The uterine artery was ligated by two ligatures using vicryl $(2,0)$ (O’Leary, 2005). Group B: A bulldog clamp was applied at the site of uterine and ovarian artery on each side for 30 minutes in order to reduce blood loss during abdominal myomectomy.

\section{Study procedures:}

Abdominal myomectomy under general anesthesia was performed in all patients according to the standard technique through transverse lower abdominal incisions
(Pfannenstiel incision). Patients were placed into dorsal lithotomy position followed by urinary catheterization. Myomectomy was done by applying longitudinal incision over the myoma. Post- operative venous blood samples of hemoglobin and hematocrit levels were withdrawn from patients after 24 hours to avoid wrong results due to hemodilution by intravenous fluids in the first 24 hours. All samples were done in the same lab. The linen towels used in the operation were weighed (in grams) before and after the operation using a highly accurate digital balance and the difference in weight between dry and soaked linen towels will be calculated. All towels used in the operation were the same regarding material, size and weight. Also, the scale used in weighting the towel was the same. Blood loss collected by suction bottle was measured in milliliters. The swabs were weighed as soon as possible after contamination with blood so that the loss by evaporation is minimized.

Blood loss during the operation was calculated as follows: Volume of the contents of the suction bottle (ml) (A). Difference in weight of linen towels (gm) (B) (weight of soaked linen towels (gm) - weight of dry linen towels $(\mathrm{gm}))$. So blood loss during operation $(\mathrm{ml})=$ $(\mathrm{A}+\mathrm{B})($ Buchman, 1953). 3. Allowable blood loss was calculated as follows [estimated blood volume $\mathrm{x}$ (initial heamoglobin-final heamoglobin)]/initial hgb. Estimated blood volume can be calculated as follows body weight $(\mathrm{kg}) \mathrm{x}$ average blood volume $(\mathrm{ml} / \mathrm{kg})$. All the patients received non-steroidal anti-inflammatory preparation in the form of (Diclofenac sodium ${ }^{\circledR}$ ) $75 \mathrm{mg}$ IM (one ampoule) immediately postoperative then one ampoule 12 hours postoperative. Estimated operative time, postoperative hospital stay, need for intraoperative or postoperative blood transfusion and need for hysterectomy were documented.

\section{STATISTICAL ANALYSIS:}

Recorded data were analyzed using the statistical package for social sciences, version 20.0 (SPSS Inc., Chicago, Illinois, USA). Quantitative data were expressed as mean \pm standard deviation (SD). Qualitative data were expressed as frequency and percentage. Probability ( $P$-value); $P$-value $<0.05$ was considered significant. $P$-value $<0.001$ was considered as highly significant. $P$-value $>0.05$ was considered insignificant.

\section{RESULTS}

Table 1 showed no significant difference between the studied groups regarding age, BMI and parity.

Table 2 showed no significant difference between the studied groups regarding myoma number, size and uterine size.

Table 3 showed that estimated intraoperative blood loss start was significantly fewer among clamping group than among ligation group. 
Table 4 showed no significant differences between the studied groups regarding preoperative and postoperative hemoglobin. Hemoglobin reduction was significantly fewer among clamping group than among ligation group.

Table 5 showed that no significant differences between the studied groups regarding preoperative and postoperative hematocrit. Hematocrit reduction was significantly fewer among clamping group than among ligation group.

Table 6 showed no significant difference between the studied groups regarding operation duration.

Table 7 showed no significant difference between the studied groups regarding hospital stay.

Table 8 showed no significant difference between the studied groups regarding side effects.

Table 1: Demographic characteristics among the studied groups

\begin{tabular}{|c|c|c|c|c|}
\hline Items & Measure & $\begin{array}{c}\text { Clamping } \\
(\mathrm{N}=45)\end{array}$ & $\begin{array}{l}\text { Ligation } \\
(\mathrm{N}=45)\end{array}$ & $P$ \\
\hline \multirow{2}{*}{$\begin{array}{l}\text { Age } \\
\text { (years) }\end{array}$} & Mean \pm SD & $31.3 \pm 4.2$ & $32.2 \pm 3.3$ & \multirow{2}{*}{$\stackrel{\wedge}{0.258}$} \\
\hline & Range & $21.0-40.0$ & $24.0-37.0$ & \\
\hline \multirow[t]{2}{*}{$\begin{array}{l}\text { BMI } \\
(\mathrm{kg} / \mathrm{m} 2)\end{array}$} & Mean \pm SD & $25.2 \pm 2.1$ & $25.1 \pm 2.2$ & \multirow{2}{*}{$\hat{0.857}$} \\
\hline & Range & $21.6-29.8$ & $20.8-29.8$ & \\
\hline \multirow[t]{2}{*}{ Parity } & Median (IQR) & $2.0(0.0-3.0)$ & $2.0(1.0-3.0)$ & \multirow{2}{*}{$\begin{array}{c}\S \\
0.572\end{array}$} \\
\hline & Range & $0.0-5.0$ & $0.0-5.0$ & \\
\hline
\end{tabular}

Table 2: Myoma number and size and uterine size among the studied groups

\begin{tabular}{lcccc}
\hline Items & Measure & $\begin{array}{c}\text { Clamping } \\
(\mathrm{N}=45)\end{array}$ & $\begin{array}{c}\text { Ligation } \\
(\mathrm{N}=45)\end{array}$ & $P$ \\
\hline Number & Median (IQR) & $3.0(1.0-3.0)$ & $2.0(1.0-4.0)$ & $\S$ \\
& Range & $1.0-5.0$ & $1.0-5.0$ & 0.845 \\
Maximum diameter & Mean \pm SD & $3.8 \pm 0.6$ & $4.1 \pm 0.7$ & $\wedge$ \\
$(\mathrm{cm})$ & Range & $2.9-6.0$ & $3.1-5.9$ & 0.118 \\
& Mean $\pm \mathrm{SD}$ & $18.8 \pm 1.6$ & $19.0 \pm 2.0$ & 1 \\
$\begin{array}{l}\text { Uterine size } \\
\text { (week) }\end{array}$ & Range & $15.0-22.0$ & $15.0-24.0$ & 0.639 \\
& & & \\
\hline
\end{tabular}

Table 3: Estimated intraoperative blood loss $(\mathrm{mL})$ among the studied groups

\begin{tabular}{cccc}
\hline Measures & $\begin{array}{c}\text { Clamping } \\
(\mathrm{N}=45)\end{array}$ & $\begin{array}{c}\text { Ligation } \\
(\mathrm{N}=45)\end{array}$ & $\wedge P$ \\
Mean \pm SD & $395.6 \pm 68.5$ & $531.8 \pm 67.5$ & $<0.001^{*}$ \\
Range & $248.0-563.0$ & $400.0-659.0$ & \\
& Value of clamping over ligation in limiting blood loss & $95 \% \mathrm{CI}$ \\
Items & Mean \pm SE & $107.7-164.7$ \\
Blood loss & $136.2 \pm 14.3$ &
\end{tabular}


Table 4: Hemoglobin (gm/dL) among the studied groups

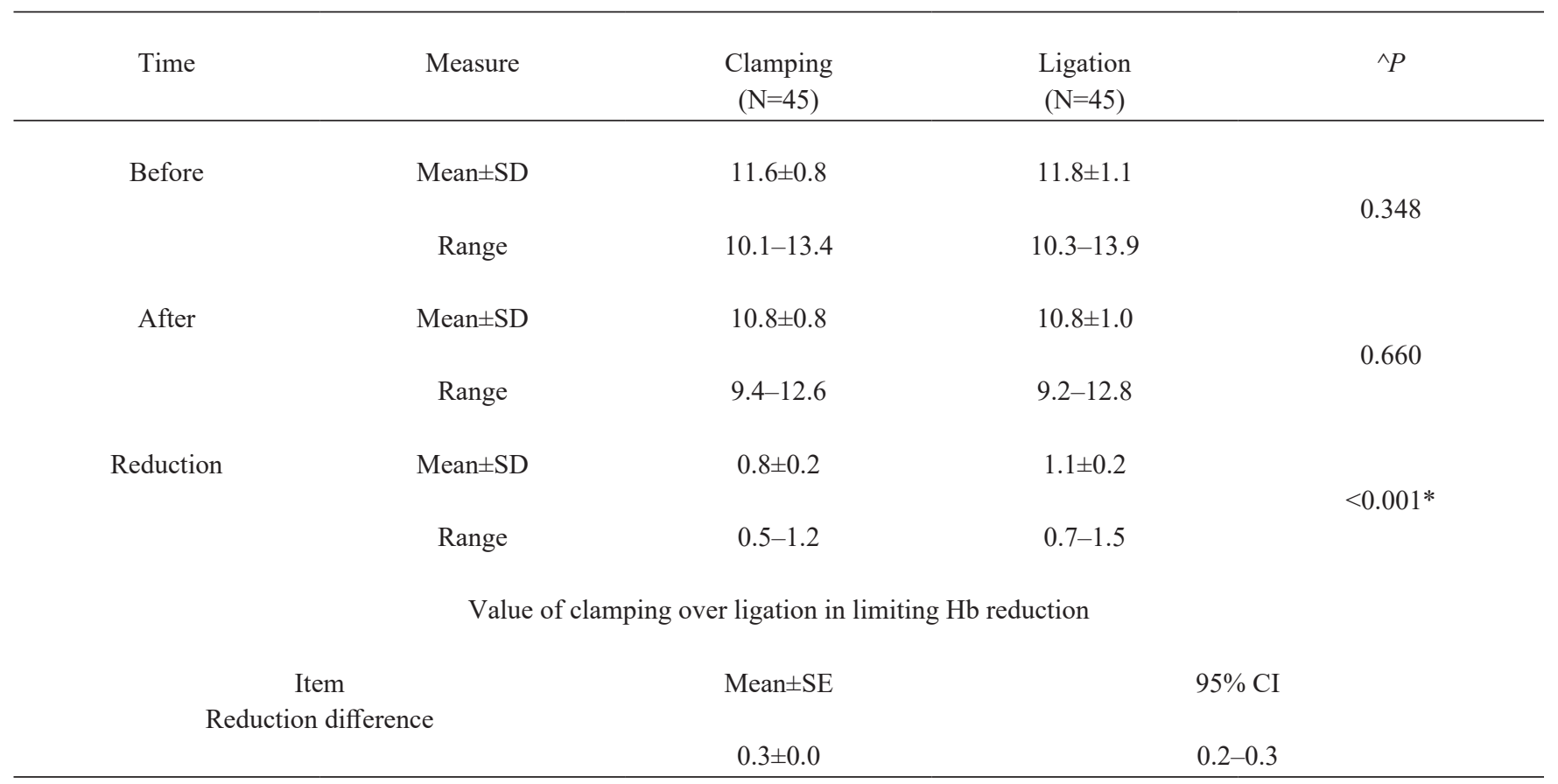

Table 5: Hematocrit (\%) among the studied groups

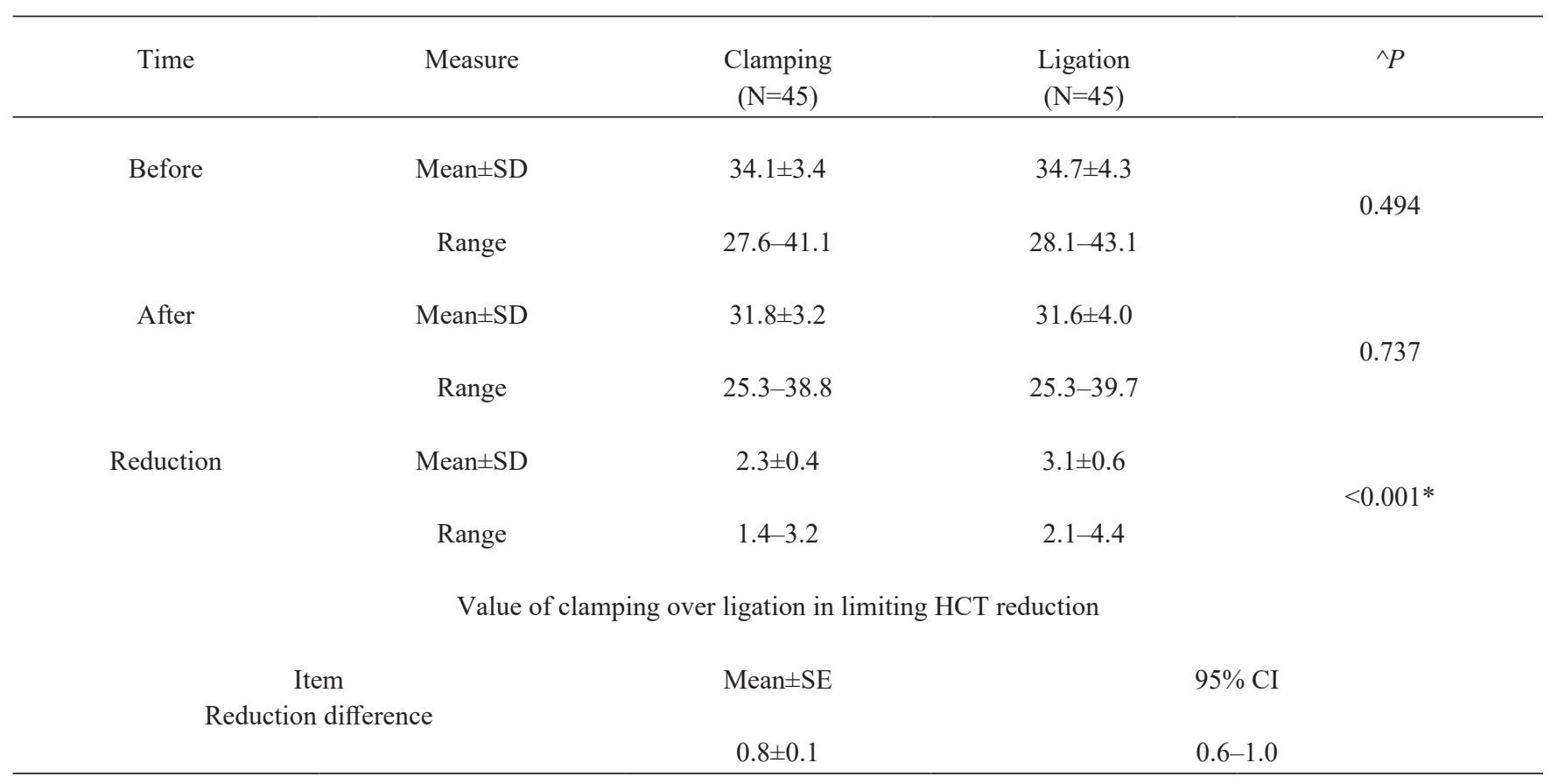


Table 6: Operation duration (minutes) among the studied groups

\begin{tabular}{ccc}
\hline Measures & $\begin{array}{c}\text { Clamping } \\
(\mathrm{N}=45)\end{array}$ & $\begin{array}{c}\text { Ligation } \\
(\mathrm{N}=45)\end{array}$ \\
Mean \pm SD & $85.1 \pm 11.9$ & $86.3 \pm 10.9$ \\
Range & $46.0-101.0$ & $48.0-116.0$ \\
& Value of clamping over ligation in shortening operation duration & \\
Items & Mean \pm SE & $95 \%$ CI \\
Duration reduction & $1.2 \pm 2.4$ & $-3.6-6.0$ \\
\hline
\end{tabular}

Table 7: Hospital stay (days) among the studied groups

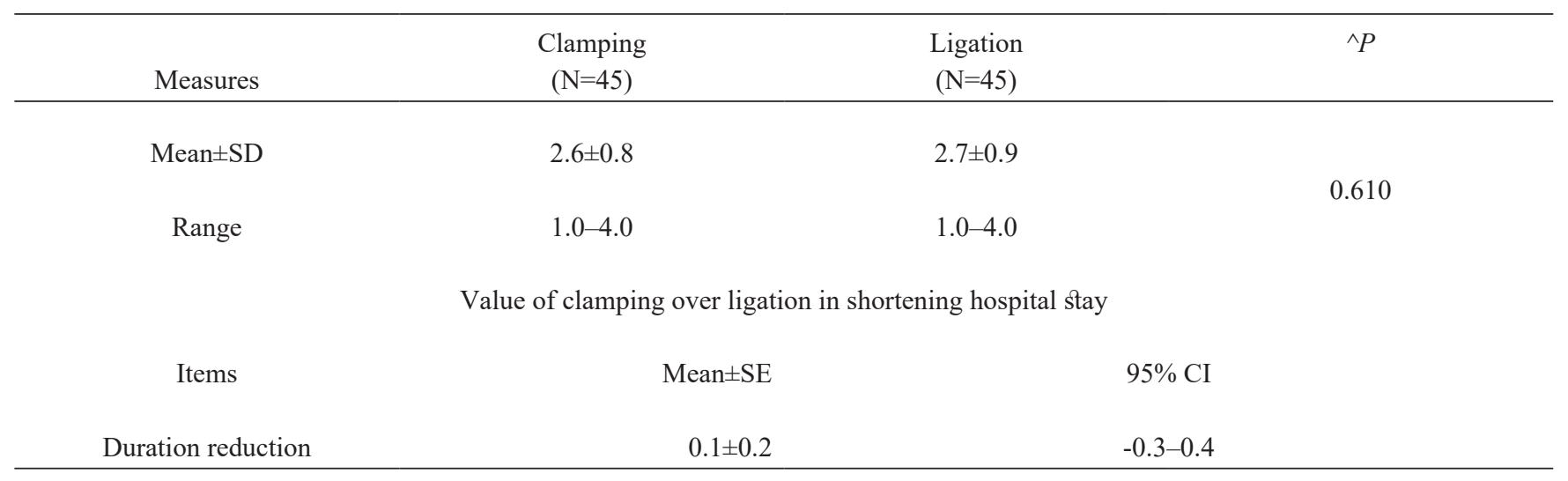

Table 8: Side effects among the studied groups

\begin{tabular}{|c|c|c|c|c|}
\hline Side effects & $\begin{array}{c}\text { Clamping } \\
(\mathrm{N}=45)\end{array}$ & $\begin{array}{c}\text { Ligation } \\
(\mathrm{N}=45)\end{array}$ & $P$ & $\begin{array}{c}\mathrm{RR} \\
(95 \% \mathrm{CI})\end{array}$ \\
\hline $\begin{array}{l}\text { Conversion to } \\
\text { hysterectomy }\end{array}$ & $0(0.0 \%)$ & $0(0.0 \%)$ & -- & -- \\
\hline $\begin{array}{l}\text { Intraoperaive } \\
\text { visceral injury }\end{array}$ & $0(0.0 \%)$ & $0(0.0 \%)$ & -- & -- \\
\hline Blood transfusion & $5(11.1 \%)$ & $7(15.6 \%)$ & $\# 0.535$ & $\begin{array}{c}0.71 \\
(0.24-2.08)\end{array}$ \\
\hline Postoperative fever & $2(4.4 \%)$ & $5(11.1 \%)$ & $\& 0.434$ & $\begin{array}{c}0.40 \\
(0.08-1.96)\end{array}$ \\
\hline
\end{tabular}




\section{DISCUSSION}

The primary outcome of this study was to compare the intraoperative blood loss in the two groups. Other secondary outcomes were also compared including the need for intraoperative blood transfusion, operative time in minutes.

Several studies investigated reducing blood loss during myomectomy yet to our knowledge no studies investigated the difference between both techniques.

In a similar study conducted by Jin et al. ${ }^{[13]}, 200$ patients with symptomatic uterine fibroids were randomly divided into Group A $(\mathrm{n}=65)$, Group B $(n=67)$ and Group C $(n=68)$. Laparoscopic myomectomy was performed in Group A, temporary bilateral uterine artery occlusion and myomectomy were performed in Group B and temporary bilateral uterine artery and utero-ovarian vessel occlusion was performed in Group C. We then evaluated operative time and perioperative bleeding. There was no significant difference in the operative time between groups $(p=0.332$ and $p=0.346$ for single-myoma and multiple-myoma, respectively) and for both single and multiple-myoma groups, the blood loss was significantly lower in Group $\mathrm{C}$ than Groups A and B $(p<0.001)$. From this study, it was concluded that laparoscopic myomectomy with temporary bilateral uterine artery and utero-ovarian vessels occlusion has the advantages of less intraoperative bleeding compared with laparoscopic myomectomy alone and laparoscopic transient uterine artery ligation and does not increase the mean operative time.

In a study conducted by Magos et al. ${ }^{[14]}$, assessment of blood loss by ovarian artery clamping was conducted. In this study, they found the median estimated blood loss for clamping $500 \mathrm{ml}$ compared to $463 \mathrm{ml}$ for tourniquet which was not significant. Blood transfusion comparison was not significant for both techniques.

In another study conducted by Parsanezhad et al. ${ }^{[15]}$, laparoscopic myomectomy after bilateral uterine artery ligation was compared with laparoscopic myomectomy alone, the average operating time and blood loss were $112 \pm 18$ minutes and $173 \pm 91 \mathrm{~mL}$ for the experimental group and $95 \pm 14$ minutes and $402 \pm 131 \mathrm{~mL}$ for the control group, respectively (statistically significant). A total of $15(17.2 \%)$ of the control group patients required a blood transfusion, but none of the experimental group patients required one. Febrile morbidity occurred in $18.5 \%$ of the experimental group and $20.7 \%$ of the control group. In the experimental group, the study demonstrated the superiority of laparoscopic uterine artery ligation combined with myomectomy in treatment of symptomatic myomas.

In a study conducted by Voss et al. 2007, clipping of uterine artery during laparoscopic myomectomy revealed preoperative HB mean $12.5 \mathrm{gm} \%$, postoperative HB $10 \mathrm{gm} \%$, operative time 273 minutes.

In a study conducted by Taylor et al. ${ }^{[16]}$, there was significant blood loss control between the triple tourniquet group and the control group. Transfusion rate was $7 \%$ compared to $79 \%$, respectively.

\section{CONCLUSION}

The ovarian artery clamp is a new instrument which can be used to reduce bleeding at open myomectomy. These clamps may have a useful role in the surgical management of this common condition because they allow for occlusion of uterine blood flow from the ovarian arteries without compromising ovarian perfusion or damaging the fallopian tubes. However, based on the results obtained by this study, intermittent clamping of uterine and ovarian artery is a preferred approach than bilateral uterine artery ligation on blood loss during abdominal myomectomy.

\section{CONFLICT OF INTEREST}

There are no conflicts of interests.

\section{REFERENCES}

1. Kwawukume EY and Emuveyan EE "Leiomyoma of the uterus Comprehensive Gynaecology in the Tropics". Accra, Asante and Hitscher. 2004; 8:23-25.

2. Lowe DG. "Benign Tumours of the Uterus." In: Edmund DK (Ed), Dewhurst Textbook of Obstetrics and Gynaecology for Postgraduates 6th Edition. London, Blackwell Sciences, 1999; 552559.

3. Dilip Visvarathar, Brown S. and Cutner A "Review of the conservative surgical treatment of uterine fibroids, Reviews in gynaecological practice", 2004; 4(1): 20-26.

4. LaMote AI, Lalwani S, Diamond MP Morbidity associated withabdominal myomectomy. Obstet Gynecol., 1993;82: 897-900.

5. Segars J, Parrott E, Nagel J, Guo X, Gao X and Birnbaum L, et al. (2014): "Proceedings from the Third National Institutes of Health International Congress on Advances in Uterine Leiomyoma Research: Human Reproduction Update; 20 (3): 309-333. 
6. Rouzi AA, A-Noury AI, Shobokshi AS, Jamal HS, Abduljabbar HS. Abdominal myomectomy versus abdominal hysterectomy for symptomatic and big uterine fibroids. Saudi Med J. 2011; 22(11):984-6.

7. Iverson R.E. Jr., Chelmow D., Strohbehn K., Waldman L., and Evantash E.G. Relative morbidity of abdominal hysterectomy and myomectomy for management of uterine leiomyomas. Obstet Gynecol 1996; 88(3): 415-9.

8. Kongnyuy E.J. and Wiysonge C.S.: "Interventions to reduce haemorrhage during myomectomy for fibroids": Cochrane Database Syst Rev 2011; CD005355.

9. Lichtinger M, Burbank F, Hallson L, Herbert S, et al. The time course of myometrial ischemia and reperfusion after laparoscopic uterine artery occlusion-theoretical implications. J Am Assoc Gynecol Laparosc, 2003; 10(4):554-63.

10. Sawin S.W., Pilevsky N.D., Berlin J.A. and Barnhart K.T.: "Comparability of perioperative morbidity between abdominal myomectomy and hysterectomy for women with uterine leiomyomas": Am J ObstetGynecol, 2000; 183: 1448 .

11. Sinha R, Sundaram M, Mahajan C, Raje S, Kadam P, Rao G. Laparoscopic myomectomy with uterine artery ligation: Review article and comparative analysis. J Gynecol Endosc Surg 2011;2:3-
12. Lee HJ, Box GN, Abraham JB, Elchico ER, Panah RA, Taylor MB, et al. Laboratory evaluation of laparoscopic vascular clamps using a load-cell device-are all clamps the same? J Urol. 2008 Oct; 180(4): 1267-72.

13. Jin L, Ji L, Shao M, Hu M. Laparoscopic Myomectomy with Temporary Bilateral Uterine Artery and Utero-Ovarian Vessels Occlusion Compared with Traditional Surgery for Uterine Fibroids: Blood Loss and Recurrence. Gynecologic and obstetric investigation. 2019; 1-7.

14. Magos A, Al-Shabibi N, Korkontzelos I, Gkioulekas N, Tsibanakos I, Gkoutzioulis A, Moustafa M. Ovarian artery clamp: initial experience with a new clamp to reduce bleeding at open myomectomy. Journal of Obstetrics and Gynaecology. 2011 Jan 1;31(1):73-6.

15. Parsanezhad M.E., Azmoon M. and Alborzi S.: "A randomized, controlled clinical trial comparing the effects of aromatase inhibitor (letrozole) and gonadotropin-releasing hormone agonist (triptorelin) on uterine leiomyoma volume and hormonal status": Fertil Steril, 2010; 93: 192.

16. Taylor A., Sharma M., Tsirkas P., Di Spiezio Sardo A., Setchell M., and Magos A. Reducing blood loss at open myomectomy using triple tourniquets: a randomized controlled trial. Br J Obstet gynaecol 2005; 112(3): 304-5. 